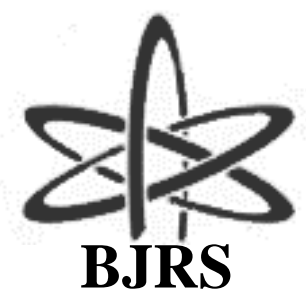
BRAZILIAN JOURNAL $\mathrm{OF}$ RADIATION SCIENCES 08-03A (2020) 01-12

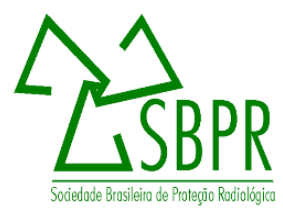

\title{
RMB experimental program on the hydrodynamical behavior of fuel assemblies
}

\author{
Walmir Máximo Torres, Pedro Ernesto Umbehaun, Miguel Mattar Neto, Antonio \\ Belchior Jr., Roberto Longo Freitas \\ Instituto de Pesquisas Energéticas e Nucleares (IPEN/CNEN - SP) \\ wmtorres@ipen.br
}

\begin{abstract}
The Brazilian Multipurpose Reactor - RMB is a $30 \mathrm{MW}$ pool type research reactor, that uses Materials Testing Reactor - MTR type fuel assemblies. It has a $5 \times 5$ square array core with 23 fuel assemblies and two in-core irradiation positions, operating with upward flow and average velocities nearly $10 \mathrm{~m} / \mathrm{s}$ in the fuel plates channels. The IEA-R1 is a 5 MW pool type research reactor, which also has a $5 \times 5$ square array core with 19 standard fuel assemblies, four control fuel assemblies and a central beryllium irradiation device. It operates with downward flow nearly $1.8 \mathrm{~m} / \mathrm{s}$ in the channels. In order to verify and provide data and information about the dynamical behavior of fuel assemblies under nominal and critical conditions, the experimental circuit ORQUÍDEA is being designed. This circuit will permit upward and downward flow and dynamical behavior of the fuel assemblies and its parts will be tested and verified. Flow rate, temperature, pressure and differential pressure transducers are the instruments of the circuit. Endurance and critical flow velocity tests will be performed. The COLIBRI experimental circuit is being designed to make tests that allow the studies of the fluid-structure phenomenology of fuel plates similar to those of the RMB fuel assemblies when subjected to high flow velocities, which can induce pressure differences between the channels formed by the fuel plates. This work presents a preliminary design for the ORQUÍDEA and COLIBRI experimental circuits to be built at the Instituto de Pesquisas Energéticas e Nucleares - IPEN of the Comissão Nacional de Energia Nuclear - CNEN.

Keywords: Brazilian Multipurpose Reactor, ORQUÍDEA experimental circuit, COLIBRI experimental circuit, fuel assembly
\end{abstract}




\section{INTRODUCTION}

The main objective of this paper is to present the ORQUÍDEA and COLIBRI experimental circuit projects to be built at Instituto de Pesquisas Energéticas e Nucleares (IPEN) of the Comissão Nacional de Energia Nuclear (CNEN).

The ORQUÍDEA experimental circuit is being designed to perform hydrodynamic tests, in low pressure and temperature, of fuel assemblies (FAs) of the type (MTR) of research reactors. The tests are important to study the behavior of the FAs under normal operating conditions, and can evaluate their behavior and performance through endurance tests and under extreme conditions, such as critical flow velocity.

The COLIBRI experimental circuit is being designed to carry out experiments that allow the studies of the deformation/vibration phenomenology of plates similar to those of the RMB fuel assemblies. Fuel assemblies subject to high flow rates may induce pressure differences between the flow channels formed by the fuel plates.

The tests are important to study the phenomenological analysis of the behavior of the RMB fuel assemblies under normal operating conditions, and can evaluate their behavior and performance through endurance tests and under extreme conditions, such as critical flow velocity and the influence of flow induced vibration on the fuel plates. For these extreme conditions, which must be avoided during the operation of the reactor, plastic deformations of the fuel plates can occur, reducing the flow area and the cooling conditions in the channel, which can cause overheating and damage to the plates with release of radioactive material.

These tests are necessary to the qualification of the FAs that will be used in the Brazilian Multipurpose Reactor (RMB).

\section{ORQUÍDEA EXPERIMENTAL CIRCUIT}

The ORQUÍDEA experimental circuit, as shown in Figure 1, is being designed to perform hydrodynamic tests, at low pressure and temperature, of the "Material Testing Reactor (MTR)" fuel assemblies (FAs) of the RMB and IEA-R1. reactors 
The ORQUÍDEA experimental circuit will use some equipment and components of the IPEN/CNEN Experimental Water Circuit, also known as LOOP 70 [1]. Part of its process instrumentation will be utilized, such as pressure and differential pressure transmitters, and temperature transmitters and meters, as well as the LOOP 70 metallic structure for fixing and mounting the circuit. The water tank and pressurizer are also used.

The Experimental Water Circuit (Circuito Experimental de Água - CEA) or LOOP 70 [1] is an experimental circuit designed to operate at high pressure and temperature. It was designed and built to conduct thermal-hydraulic experiments simulating the operation conditions of pressurized light water reactors, PWR and BWR. The LOOP 70 is installed in the IPEN/CNEN-Centro de Engenharia Nuclear (CEN) shed and consists of a main circuit with a testing section, water purification systems, storage and deaeration tank, pressurizer, preheater, heater, and secondary cooling system. In addition, there are electric power supply, control system, instrumentation and safety systems. The Storage Tank/Deaerator (V-101) and the Pressurizer (V-102) will be used to compose the ORQUÍDEA experimental circuit. A detailed mechanical evaluation was done for the Storage Tank/Deaerator [2] and for the Pressurizer [3] through the structural analysis of the internal and external mechanical parts thereof, applying the original design code ASME VIII Division 1 [4].

With the use of these items, it is expected to achieve a significant reduction in costs, in addition to reducing the time required for its construction. The equipment and components of the LOOP 70 must be disconnected from it and connected to the ORQUÍDEA. The reversal of this change should be simple in order to maintain the original characteristics of the LOOP 70. The ORQUÍDEA should have electrical power and independent data acquisition systems, so that it can be operated in a simple and totally independent manner and with reduced number of operators. Calculations on the operating conditions of the equipment and components and their feasibility for use in the ORQUÍDEA are presented in reference [5].

\subsection{Bases of Design}

The ORQUÍDEA should be designed to meet the following bases of project:

1. Provide flow rates of up to $265 \mathrm{~m}^{3} / \mathrm{h}$. The head of the pump will be determined after calculations of pressure drop in the circuit (12 bar - preliminary value). The motor pump assembly shall be provided with a frequency inverter to control the rotation and consequently of the flow rate in the circuit, besides reducing the energy consumption; 


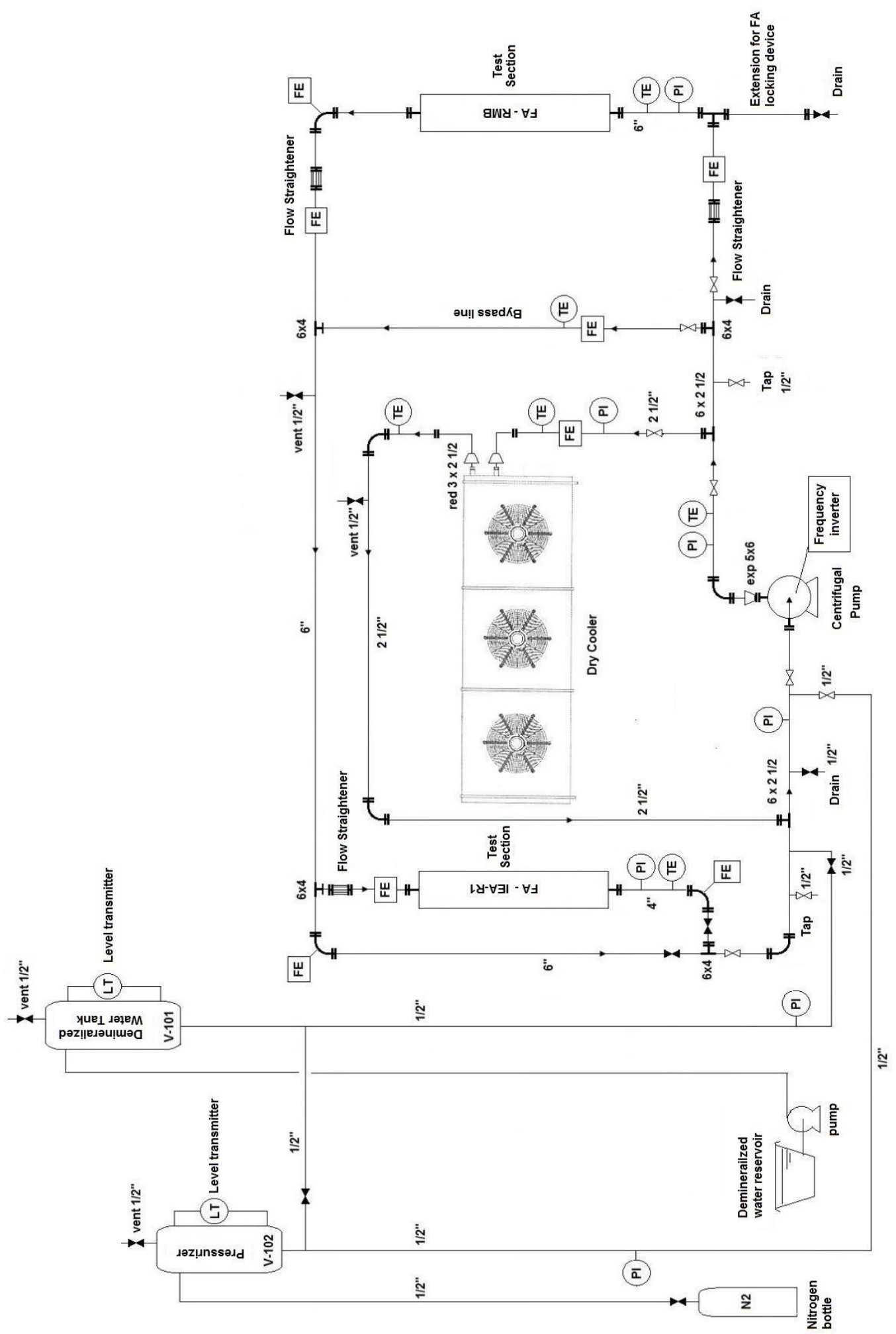

Figure 1: Schematic drawing of the ORQUÍDEA experimental circuit. 
2. The circuit also has a bypass line to aid in flow rate control in the tests;

3. The process fluid temperature of the operating circuit must be in the range between 40 and $60{ }^{\circ} \mathrm{C}$;

4. Stainless steel 304 tubes shall be designed in accordance with ASME B31.1 with 6 and 4 inches Schedule 40 diameters. Circuit should have drains in lower parts and vents in the upper parts. Valves are provided along the circuit to assist in its operation;

5. The circuit uses demineralized water as the process fluid. It will be produced by the demineralized water production system of the IPEN/MB-01 reactor and will feed the storage tank / deaerator;

6. The circuit has a pressurizer, which will be pressurized with gas (Nitrogen), connected in the line suction pump to accommodate the fluid density circuit variations due to temperature;

7. The circuit has a secondary cooling system for the removal of heat generated by the pumping process. A heat exchanger type liquid to air (Dry Cooler) should be used;

8. The circuit will have one or more test sections depending on the test being performed with the FAs. A line must be provided for the installation of a section of tests for experiments with FAs $s$ that operate with downward flow (Ex: FAs from the IEA-R1 reactor). The instrumentation of the test sections should be specific to for each type of FAs test;

9. The circuit is designed to allow assembly and disassembly of simplified, as well as its operation. The piping must be designed in spools. When necessary, there must be connections for the installation of the instrumentation. Extra connections must be provided along the circuit to enable installation of additional instrumentation;

10. The circuit has flow meters with flow straighteners, pressure and differential pressure, temperature gauges, and level gauges;

11. The power supply of the circuit will be independent; and

12. Two independent data acquisition systems shall be used to record the process variables of the circuit and to record the parameters of the tests with the FAs. 


\subsection{System Operation}

In the experimental circuit ORQUÍDEA will tested FAs of the MTR type of research reactors. In these tests, the water flow rate is the main parameter, it being desirable that the temperature of the process fluid is maintained constant. Pressure drop versus flow rates should be obtained for FAs as a whole, or parts thereof (for example: inlet nozzles, fuel plate region, output region, clamping mechanism, and etc.).

The behavior of the plates also depends on the flow through the FAs. In addition, it is of interest to verify the critical flow velocity for the FAs, which for the MTR type of the RMB should be between 15 and $20 \mathrm{~m} / \mathrm{s}$ (200 and $265 \mathrm{~m}^{3} / \mathrm{h}$ ). Endurance testing should be carried out with the operating flow of $125 \mathrm{~m}^{3} / \mathrm{h}$, which results in an average velocity in the channels of $9.4 \mathrm{~m} / \mathrm{s}$. In this way, the flow rate will be treated as a parameter that can vary within a range of values, depending on the test to be accomplished.

The circuit has a motor-pump assembly, capable of $265 \mathrm{~m}^{3} / \mathrm{h}$ and 12 bar of head (value to be confirmed), equipped with a frequency inverter for control and flow variation. In addition, there is a by-pass line to adjusting the flow through the test sections.

\subsection{Fuel Assemblies in the Experimental Circuit ORQUÍDEA}

\subsubsection{RMB Fuel Assemblies}

Due to the presence of radioactive materials in the RMB fuel assemblies, the tests will be carried out with a prototype of the RMB fuel assemblies, which will be made in aluminum by the IPENCentro do Combustível Nuclear (CCN). Figure 2 shows a side view schematic of the RMB fuel assembly and Table 1 presents its main characteristics.

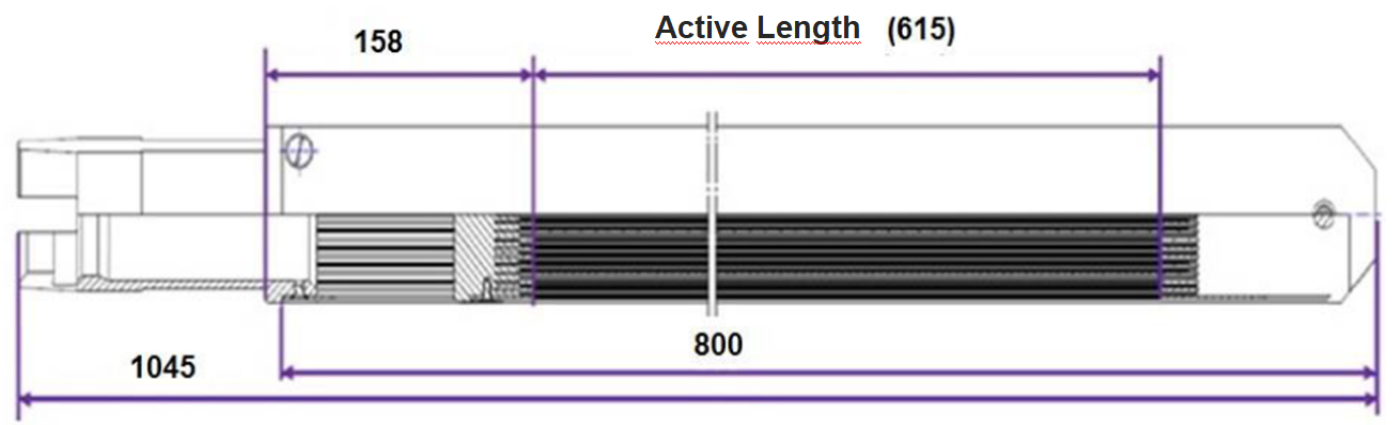

Figure 2: RMB fuel assembly. 
Table 1: Characteristics of RMB fuel assembly.

\begin{tabular}{|c|c|c|}
\hline Assembly Type Fuel & \multicolumn{2}{|c|}{$\mathrm{MTR}$ - core $\mathrm{U}_{3} \mathrm{Si}_{2}$} \\
\hline Dispersion (fissile compound - matrix) & \multicolumn{2}{|c|}{$\mathrm{U}_{3} \mathrm{Si}_{2}-\mathrm{Al}$} \\
\hline 235U average enrichment & \multicolumn{2}{|c|}{19.75 (\% by weight) } \\
\hline Maximum density of uranium in the core & \multicolumn{2}{|c|}{$4.8 \mathrm{gU} / \mathrm{cm}^{3}$} \\
\hline $\begin{array}{l}\text { Dimensions }(\mathrm{mm}) \\
\text { (side } \mathrm{x} \text { side } \mathrm{x} \text { height) }\end{array}$ & \multicolumn{2}{|c|}{$80.5 \times 80.5 \times 1045$} \\
\hline Geometry of the fuel plate & \multicolumn{2}{|c|}{ Flat plate } \\
\hline Arrangement of plates & \multicolumn{2}{|c|}{ Parallel } \\
\hline Number of plates & \multicolumn{2}{|c|}{21} \\
\hline \multirow{2}{*}{$\begin{array}{l}\text { Dimensions of fuel plates } \\
\text { (thickness x width x length) }\end{array}$} & $\begin{array}{l}\text { Internal Plate } \\
(\mathrm{mm})\end{array}$ & $\begin{array}{c}\text { External Plate } \\
(\mathrm{mm})\end{array}$ \\
\hline & $1.35 \times 75 \times 655$ & $1.50 \times 75 \times 825$ \\
\hline Active length & $615 \mathrm{~mm}$ & $615 \mathrm{~mm}$ \\
\hline Cladding Material & \multicolumn{2}{|c|}{$\mathrm{Al} 6061 \mathrm{~T} 0$} \\
\hline \multirow{2}{*}{ Cladding thickness near the core } & $\begin{array}{l}\text { Internal Plate } \\
\quad(\mathrm{mm})\end{array}$ & $\begin{array}{l}\text { Internal Plate } \\
(\mathrm{mm})\end{array}$ \\
\hline & 0.370 & 0.370 \\
\hline $\begin{array}{l}\text { Core dimensions }(\mathrm{mm}) \\
\text { (thickness } \mathrm{x} \text { width } \mathrm{x} \text { length) }\end{array}$ & \multicolumn{2}{|c|}{$0.61 \times 65 \times 615$} \\
\hline Distance between centers of fuel plates & \multicolumn{2}{|c|}{$3.8(\mathrm{~mm})$} \\
\hline $\begin{array}{l}\text { Thickness } x \text { width of the cooling channel } \\
(\mathrm{mm})\end{array}$ & \multicolumn{2}{|c|}{$2.45 \times 70$} \\
\hline Lateral support material & \multicolumn{2}{|c|}{ Al 6061 T6 } \\
\hline $\begin{array}{l}\text { Dimensions of side support plate }(\mathrm{mm}) \\
\text { (thickness } \mathrm{x} \text { width } \mathrm{x} \text { length) }\end{array}$ & \multicolumn{2}{|c|}{$5.0 \times 80.5 \times 890$} \\
\hline $\begin{array}{l}\text { Fuel plate grooves on side support plate } \\
\text { (width } \mathrm{x} \text { depth) }\end{array}$ & $\begin{array}{c}\text { Internal Plate } \\
(\mathrm{mm}) \\
1.45 \times 2.5 \\
\end{array}$ & $\begin{array}{c}\text { External Plate } \\
(\mathrm{mm}) \\
1.60 \times 2.5 \\
\end{array}$ \\
\hline Burnable poison material (wires) & \multicolumn{2}{|c|}{ Cadmium } \\
\hline Slot dimensions for $\mathrm{Cd}$ wires $(\mathrm{mm})$ & \multicolumn{2}{|c|}{$0.508 \times 0.408$} \\
\hline Wire dimensions (diameter $\mathrm{x}$ length) $(\mathrm{mm})$ & \multicolumn{2}{|c|}{$\begin{array}{c}0.4 \times 492 \text { (centered in relation to } \\
\text { the active length) }\end{array}$} \\
\hline Number of Cd strings in FA & \multicolumn{2}{|c|}{42 ( 21 wires in each side bracket) } \\
\hline
\end{tabular}




\subsubsection{IEA-R1 Fuel assemblies}

Similarly, the prototype of the fuel assembly of the IEA-R1, without fissile material, will be made in aluminium by the IPEN Nuclear Fuel Center. Figure 3 shows a schematic view of the fuel assembly of the IEA-R1 and Table 2 shows its main characteristics.

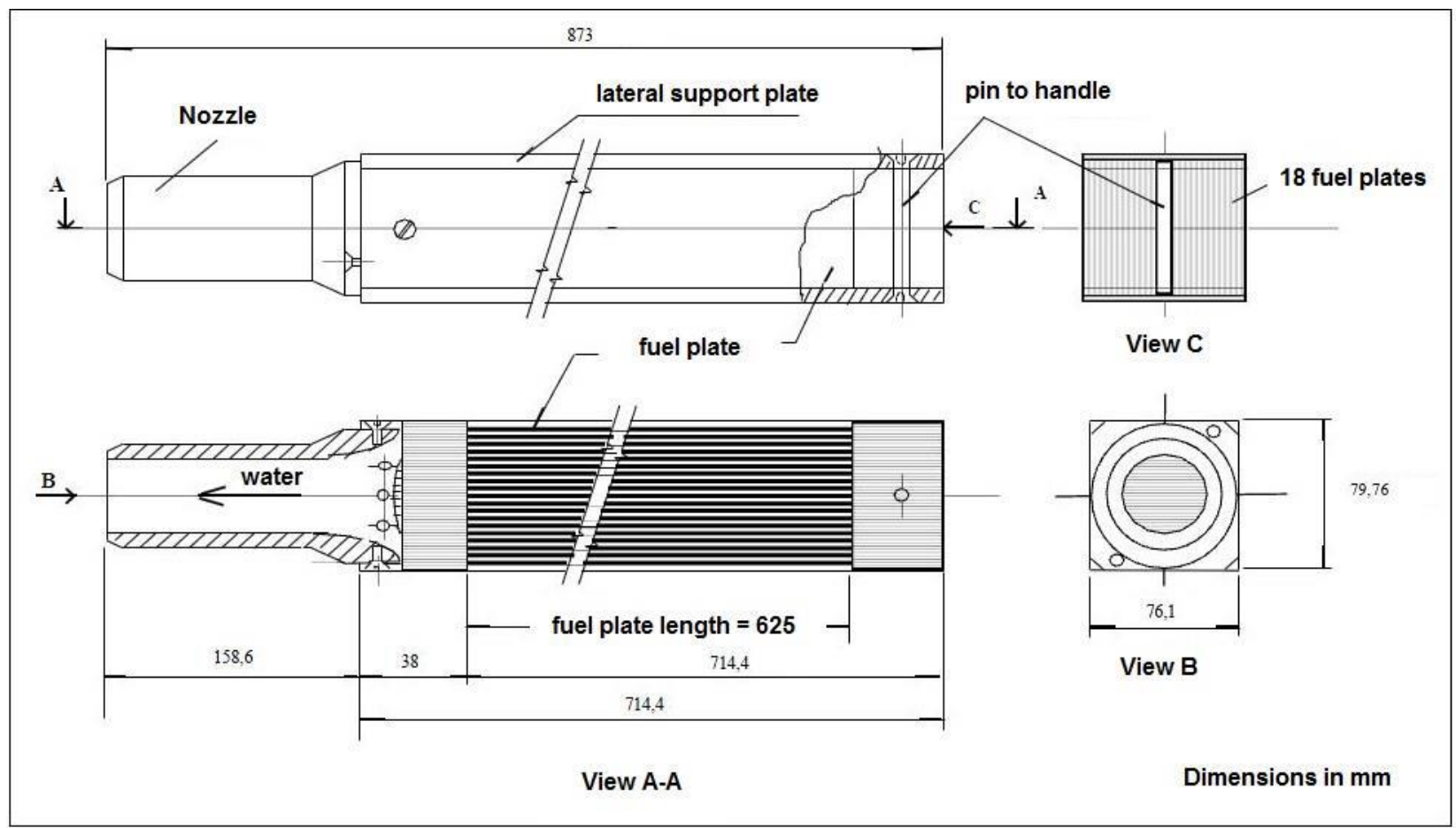

Figure 3: Schematic view of the IEA-Rl fuel assembly.

Table 2: Characteristics of IEA-R1 fuel assemblies.

\begin{tabular}{|l|c|}
\hline \multicolumn{2}{|c|}{ NUCLEAR FUEL TYPE } \\
\hline Chemical composition & $\mathrm{U}_{3} \mathrm{Si}_{2}$ \\
\hline \multicolumn{2}{|c|}{ FUEL MATERIALS } \\
\hline Country of origin & Brasil \\
\hline Fuel shape & $\begin{array}{c}\text { Dispersion } \\
\text { In } \mathrm{Al}\end{array}$ \\
\hline Density of Uranium $\left(\mathrm{gU} / \mathrm{cm}^{3}\right)$ & 3.0 \\
\hline Mass fraction of uranium $(\%)$ & 56.61 \\
\hline Enrichment & 19.75 \\
\hline
\end{tabular}




\begin{tabular}{|l|c|}
\hline \multicolumn{2}{|c|}{ FUEL PLATE } \\
\hline Mass of uranium $(\mathrm{g})$ & 78.71 \\
\hline Mass of ${ }^{235} \mathrm{U}(\mathrm{g})$ & 15.54 \\
\hline Active width (mm) & 60.35 \\
\hline Active length (mm) & 590 \\
\hline Cladding material & ASTM 1060 \\
\hline Coating thickness & 0.38 \\
\hline Core thickness & 0.76 \\
\hline & \\
\hline Number of fuel plates & 18 \\
\hline Total mass of uranium (g) & 1416.78 \\
\hline Total mass of ${ }^{235} \mathrm{U}(\mathrm{g})$ & 279.72 \\
\hline Cooling channel thickness (mm) & 2.89 \\
\hline Cooling channel width (mm) & 66.90 \\
\hline Hydraulic cooling channel diameter (mm) & 5.54 \\
\hline Support plate material & ASTM 6262 T6 \\
\hline Nozzle material & ASTM 6262 T6 \\
\hline Mean gap between assemblies (mm) & 5.9 \\
\hline Mass of one assembly (Kg) & CORE 4 \\
\hline Total number of Standard FAs and Control FAs & \\
\hline
\end{tabular}

\subsubsection{MTR-type FA tests}

The operation of the circuit, when it is in tests with RMB MTR type FAs (upflow), depends on the type of test to be performed. If the tests are designed to obtain pressure drop curves as a function of the flow of the FA as a whole or of its parts, the circuit should have its flow adjusted to values within a range of 50 to $150 \mathrm{~m}^{3} / \mathrm{h}$, with steps of 10 or $20 \mathrm{~m}^{3} / \mathrm{h}$, for example. The flow rate will be adjusted using the frequency inverter that changes the pump speed, assisted by the bypass line if necessary. A portion of $30 \mathrm{~m}^{3} / \mathrm{h}$ is diverted in the discharge line of the pump and passes through the heat 
exchanger to remove the heat generated by the pumping process. This heat is dissipated into the atmosphere as hot air.

In the tests for the verification of the behavior in normal operation or resistance, the flow through the FA must be kept constant and equal to the nominal operating flow, that is, $125 \mathrm{~m}^{3} / \mathrm{h}$. Removal of the heat generated by the pumping is similar to that mentioned above, as is the bypass flow through the heat exchanger.

The tests to verify the critical flow velocity will be carried out with higher flow rates, such that flow velocities in the flow channels are between 15 and $20 \mathrm{~m} / \mathrm{s}$, corresponding to 200 and $250 \mathrm{~m}^{3} / \mathrm{h}$ respectively.

For tests with IEA-R1 MTR-type FAs, the downward flow test section shall be used. In this case, the maximum flow rate will be of the order of $30 \mathrm{~m}^{3} / \mathrm{h}$. Steps of $5 \mathrm{~m}^{3} / \mathrm{h}$ can be used to obtain pressure loss versus flow curves.

\section{COLIBRI EXPERIMENTAL CIRCUIT}

The experimental circuit COLIBRI as shown in Figure 4, aims to perform experiments that allow the study of the deformation/vibration phenomenology of plates similar to those of RMB fuel assemblies when subjected to velocities that may induce pressure differences in the channels of flow between the fuel plates.

The COLIBRI has as main objective to provide experimental data of the fields of velocity, pressure and temperature between the fuel assemblies of $\mathrm{RMB}$ in order to validate the numerical procedures related to CFD (Computational Fluid Dynamics) codes under and accidental conditions [6] and [7].

Preliminary structural response studies of the plate's behavior were performed using a Finite Element Analysis model generated by ANSYS Mechanical. The pressure loadings caused by the fluid flow were calculated using a Computational Fluid Dynamics model created with ANSYS CFX.

The fluid-structure interactions will be verified for different channel configurations. In this circuit, vibrations and collapse of the dummy fuel plates will be tested. Experimental data will be compared with CFD (Computational Fluid Dynamics) calculations. 
This circuit is currently in the detailed project phase, aiming to specify the purchase of materials, equipment and instrumentation. The assembly, installation and commissioning of the COLIBRI experimental circuit will be carried out by IPEN/CEN technicians.

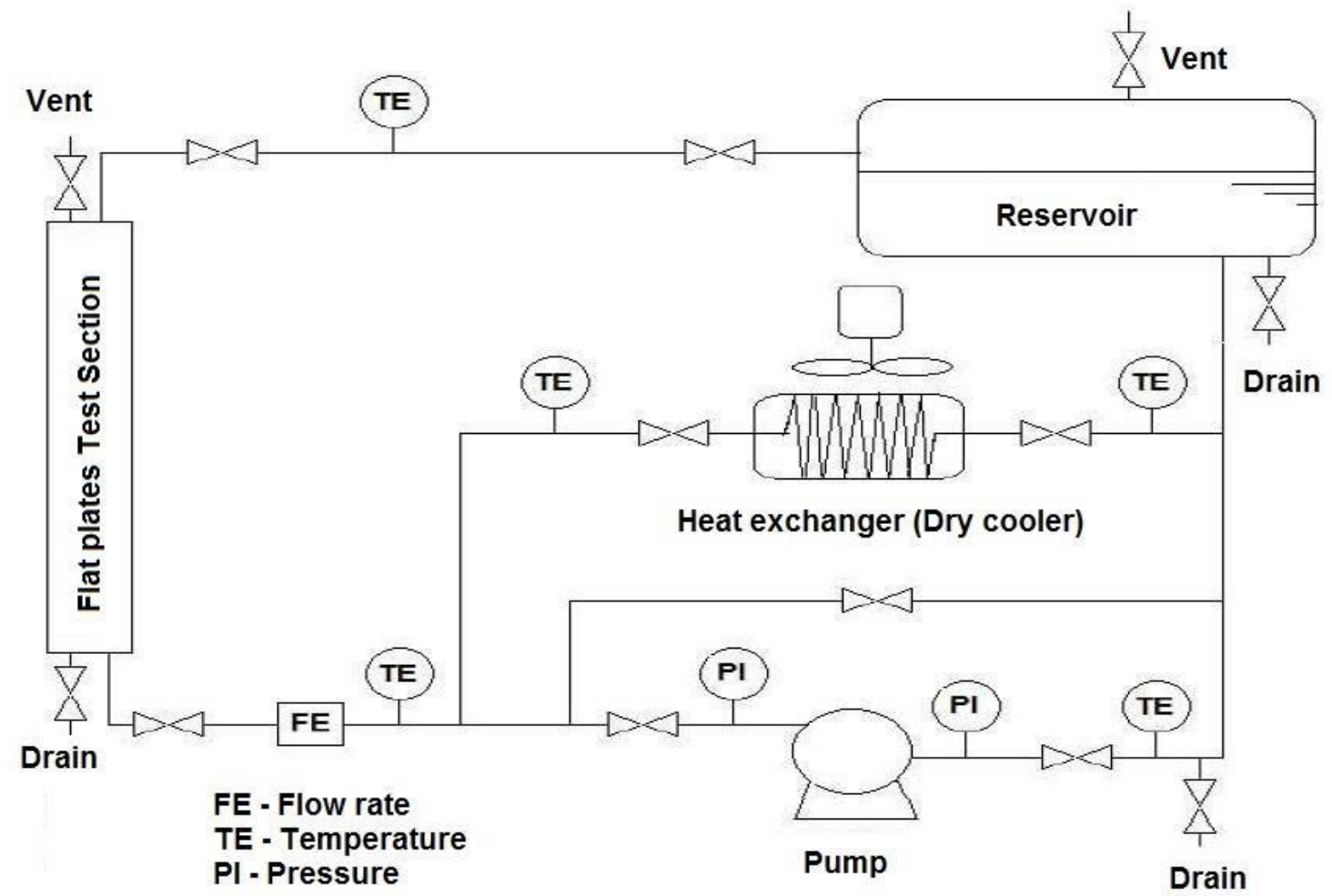

Figure 4: Schematic drawing of the COLIBRI experimental circuit.

\section{CONCLUSION}

The purpose of this document is to describe the main thermal-hydraulic circuits ORQUÍDEA and COLIBRI that must be implemented in Experimental Program of the Brazilian Multipurpose Reactor Project (RMB).

This Experimental Program will produce data and information for fuel assembly qualification, validation and support for the Final Safety Analysis Report - FSAR with CNEN when licensing the Brazilian Multipurpose Reactor Project. 


\section{ACKNOWLEDGMENT}

The authors would like to thank Dr. José Augusto Perrotta, RMB Technical Coordinator, for the encouragement and support in the definition of the Experimental Program of the Brazilian Multipurpose Reactor.

\section{REFERENCES}

[1] Descrição do Circuito Experimental do IPEN - Relatório. IPEN Internal Report. 1981/1982.

[2] FAINER, G.; FALOPPA, A. A.; ALMEIDA, J. T. D. Circuito Orquídea: Avaliação Estrutural do Tanque de Armazenamento/Desaerador V-101. IPEN Internal Report. 05/07/2018.

[3] FAINER, G.; FALOPPA, A. A.; ALMEIDA, J. T. D. Circuito Orquídea: Avaliação Estrutural do Pressurizador V-102. IPEN Internal Report. 05/07/2018.

[4] ASME Boiler and Pressure Vessel Code, Section VIII, Division 1, "Rules for Construction of Pressure Vessels". [S.1.]: The American Society of Mechanical Engineers, 2007.

[5] FREITAS, R. L. Circuito Experimental ORQUÍDEA para Testes de Elementos Combustíveis. IPEN Internal Report. 03/05/2018.

[6] MANTECÓN, J. G. \& MATTAR NETO, M. Numerical methodology for fluid-structure interaction analysis of nuclear fuel plates under axial flow conditions. Nuclear Engineering and Design, p. 76-86, 2018.

[7] MANTECÓN, J. G.; MATTAR NETO, M. Numerical Analysis on Stability of Nuclear Fuel Plates with Inlet Support Comb. Nuclear Engineering and Design, p. 240-248, 2019. 